Faculty of Philology

University of Belgrade

Serbia

Andrej Bjelaković**

Faculty of Philology

University of Belgrade

Serbia

\title{
PRONUNCIATION MODEL SELECTION, OR DO YOU SPEAK AMERICAN?
}

\begin{abstract}
Presented are the results of a survey about English pronunciation attitudes and preferences aimed at first-year students of English language and literature. The main aim of the survey was to shed light on the advance of General American (GA) as the preferred pronunciation model in recent years. The survey questions cover the main features that distinguish GA from SBS (Southern British Standard), such as rhoticity, t-voicing, articulation of the BATH and LOT vowels as well as the presence of the low back merger. The majority of respondents report that they prefer using GA, while they prefer listening to SBS. The results suggest, however, that the majority of test subjects use a mixture of sorts, with few students being consistent in their usage of specific pronunciation features.
\end{abstract}

Key words: rhoticity, t-voicing, BATH vowel, LOT vowel, low back merger, GA, SBS, Serbian EFL speakers

\section{Introduction}

The noticeable rising popularity of the American English pronunciation model among the students of the English Department in Belgrade has triggered this research study. The main aim of this paper is to find out whether this assumption can be proved by analyzing the most conspicuous consonantal and vocalic differences between Southern British Standard (SBS) and General American (GA) in the choices of our respondents. These include rhoticity and t-voicing in the domain of consonants, and the articulation of the BATH and LOT vowels as well as the presence of the low back merger.

\footnotetext{
${ }^{*}$ Faculty of Philology, University of Belgrade, Studentski trg 3, 11000 Belgrade, Serbia; e-mail: biljana. cubrovic@fil.bg.ac.rs

** Faculty of Philology, University of Belgrade, Studentski trg 3, 11000 Belgrade, Serbia; e-mail: b.andrej@ fil.bg.ac.rs
} 
Standard British English pronunciation (formerly referred to as RP) has been a target for many L2 speakers for many decades. Serbian EFL speakers were no exception. Traditionally, English Phonetics and pronunciation classes have been based on the description and transcription of SBS since the foundation of the English Department in Belgrade in 1929. The first phonetic materials were published in 1957 in the form of a phonetic reader, with a short overview of the main phonetic characteristics of Received Pronunciation (Anastasijević and Gimson 1957). Shortly after that Mihailović (1966) and Vidović (1967) published their own textbooks. Mihailović (1966) has a theoretical approach to the description of the phonemic elements of Received Pronunciation. Vidović (1967) nicely marries theory and practice of Standard Southern English Pronunciation. Hlebec (1995) was the first author of the Belgrade phonetics school to include a chapter on the speech varieties of English, where he presents the differences between British English (RP) and American English (GA) from a phonetic perspective. The current textbook shyly introduced the most dominant differences between these two varieties (Čubrović 2018), with the aim of explaining to the students those phonetic phenomena that they use in their speech and which are not necessarily found in SBS. Our classroom experience shows that students react to the examples of t-voicing more readily compared to glottal stops, which is one of the signature features of SBS.

In relation to the choice of the variety of English that is taught in the EFL classroom, Cruttenden says that "those countries which have traditionally been influenced by the U.S. may well use a version of General American (GA) as a model" (2014: 326). Collins and Mees (2013: 7) add to Cruttenden's observation that the expansion of American English is present in other parts of the world: "General American is also used as a model by millions of students learning English as a second language - notably in Latin America and Japan, but nowadays increasingly elsewhere". The criteria for the selection of a particular variety of English to be taught are not as strict, but the much-debated Jenkins' (2000) grasp on a more lenient phonology of English as an International language is still not fully accepted. However, Cruttenden (2014: 327) recognizes the emergence of Amalgam English and International English as more realistic targets for those speakers who "have no realistic possibility or necessity to acquire a standard native-speaker-like accent".

\section{Methodology}

A written questionnaire was distributed among first-year students in the English department, Faculty of Philology, University of Belgrade, which yielded a total of 88 responses. Even though the respondents had been familiarized with the phonetic terminology, we avoided using any terms that might confuse or intimidate them. The 
questionnaire comprised a total of 14 questions, 10 of which dealt with specific features of SBS/GA which are going to be discussed in this paper.

Questions 1-3 deal with students' general preferences and attitudes regarding the two main standard pronunciation varieties of English, or reference accents in Wells' terminology (1982). Questions 4-10 deal with individual pronunciation features.

In Question 1 we asked our experimental subjects to answer the following question: "Which of these varieties of English do you use more often?". Two options were offered: "SBS" (i.e. Southern British Standard), and "GA" (i.e. General American) $)^{1}$. The aim of this question was to gather self-reported data on the relative frequency of use among students of the two main standard varieties of English. The students' answer to the first question was used to separate them into two groups, that we later used to elaborate on the results. If they answered "SBS" they would belong to what was designated as the "SBS Group", while students who answered "GA" formed the "GA Group". 26\% said they used SBS more often; 74\% said they used GA more often.

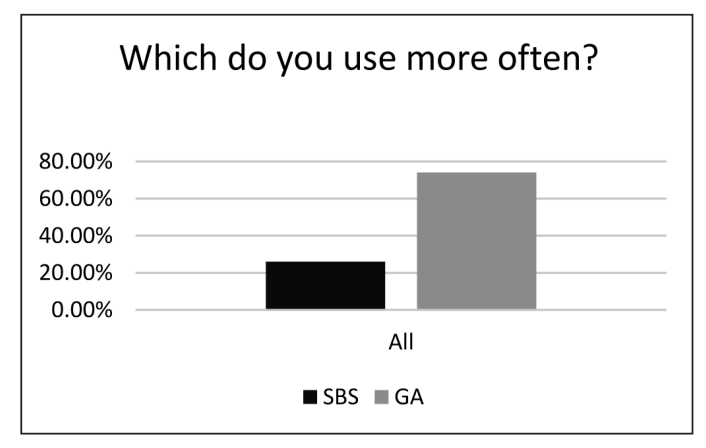

Graph 1. Preferred variety of English respondents use

Question 2 was similar, but this time we asked our respondents which variety they thought they were more exposed to. Again, two options were offered: "SBS" and "GA". $4.5 \%$ of the SBS group said they were used to hearing SBS more often, while $95.5 \%$ said they heard GA more often. $7.5 \%$ of the GA group said they heard SBS more often, while $92.5 \%$ said they heard GA more often. In other words, the two groups largely agree they are overwhelmingly exposed to GA.

\footnotetext{
${ }^{1}$ The students had already been familiarized with the terms, having had one semester of Phonetics and Pronunciation (the questionnaire was distributed halfway through the second semester).
} 
Biljana Čubrović \& Andrej Bjelaković

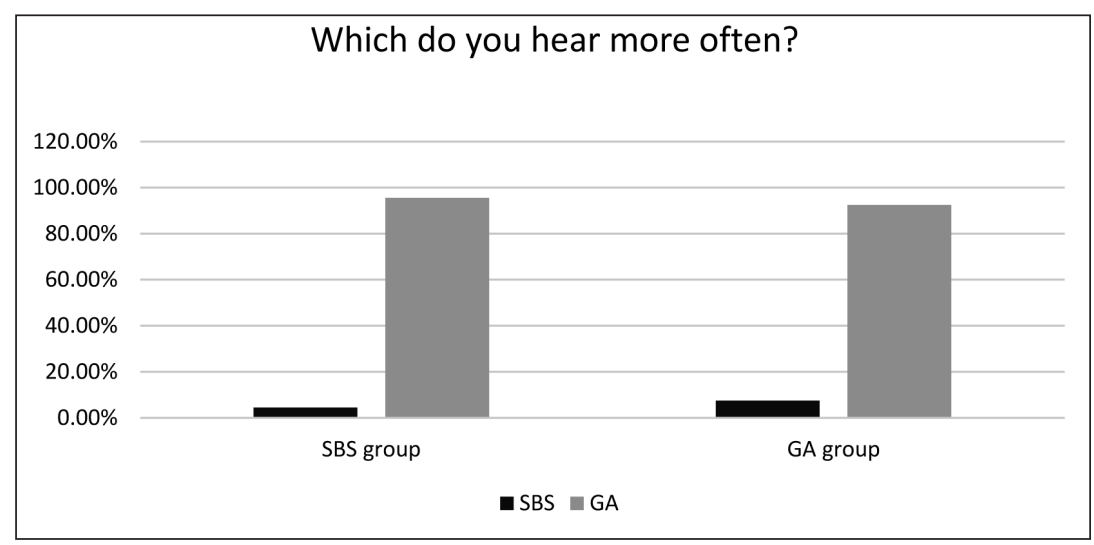

Graph 2. Variety respondents are more exposed to

The aim of Question 3 was to find out about our respondents' attitude towards the two reference accents. The same two options were provided ("SBS" and "GA"). Everybody in the SBS group said they preferred listening to SBS; on the other hand, $54 \%$ of the GA group opted for SBS as well, and the remaining $46 \%$ said they preferred listening to GA, the variety they normally spoke. That is to say, SBS seems to be the variety deemed more appealing.

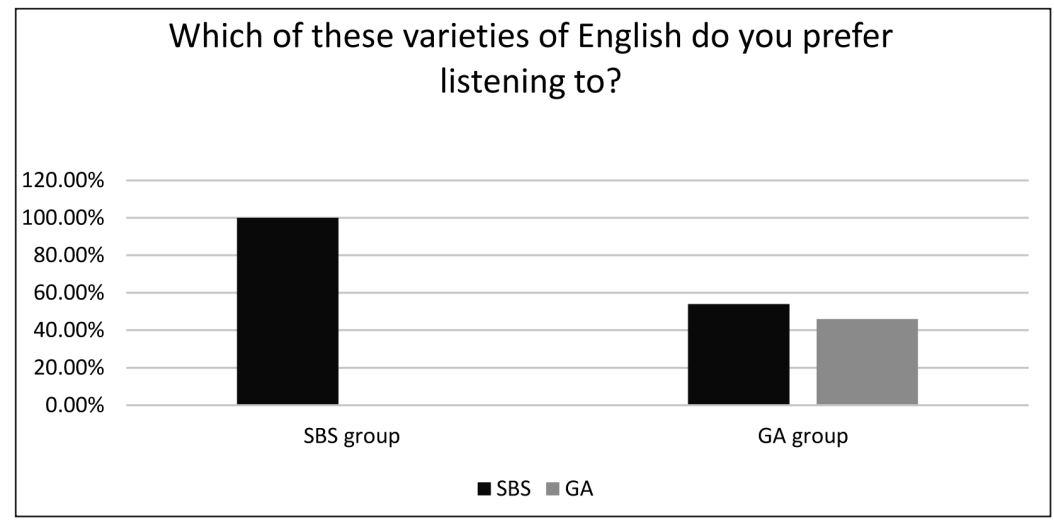

Graph 3. Preferred variety of English respondents listen to

The aim of other questions (4-10) is to explore several phonetic characteristics where SBS and GA differ most. These include the presence or absence of rhoticity (question 4), t-voicing (question 5), realization of the SBS LOT vowel (questions 6 and 9), LOT-THOUGHT merger (questions 7 and 8), and TRAP-BATH split (question 10). We will now explain the demands of questions 4-10 in full detail. 
Question 4: "Do you pronounce all your 'r' sounds in English?". The answers provided were "Yes" and "No". In other words, the students were reporting on whether their English speech was fully rhotic or not.

Question 5: "Which sound do you use in the middle of words such as city, beautiful, water, better?". The options offered were "a t-like sound" and "a d-like sound". The aim was to see if students use t-tapping (pronouncing /t/ as an alveolar tap $[r]$ ) in the cited words (a feature categorically present in GA, but found in SBS in only specific circumstances (see Hannisdal 2006; Bjelaković 2018).

Question 6: "Which sound do you use in words such as God, job, shot?". The answers were "an o-like sound" and "an a-like sound". The aim was to elicit a response regarding the vowel in the lexical set LOT, that is, if students used the unrounded, GAstyle /a:/ or a rounded, closer vowel, like the one realized in SBS.

Question 9: "How do you pronounce the underlined vowel in the word following". The answers and the aim were the same as in Question 6, however this time a somewhat less frequent word was chosen.

Question 10: "Which sound do you use in words such as ask, bath, answer?". The options offered were "an e-like sound" and "an a-like sound". The aim of the question was to determine if the student used the TRAP-BATH split characteristic of SBS (i.e. /a:/ in the cited words).

Questions 7 and 8: "How do you pronounce the words bot - bought?" and "How do you pronounce the words collar - caller?". The answers were "same" and "different". These questions were meant to be diagnostic for the feature increasingly present in North American English, the so-called low back merger (also known as the cot-caught merger or the LOT-THOUGHT merger).

\section{Results and discussion}

\subsection{Rhoticity}

Rhoticity is one of the phonetic characteristics that distinguishes standard British English pronunciation from the American English pronunciation model. Rhoticity refers to a presence or absence of non-prevocalic / $\mathrm{r} /$; according to this criterion accents of English can broadly be divided into rhotic and non-rhotic accents. SBS is a nonrhotic accent, while GA is a fully rhotic accent. This means that SBS "has eliminated historical / $\mathrm{r} /$ except in the environment of a following vowel. This came about in the eighteenth century, when $/ \mathrm{r} /$ disappeared before a consonant or in absolute final position" (Wells 1982: 218). Conversely, we find all historical/r/ sounds intact in $\mathrm{GA}^{2}$.

\footnotetext{
${ }^{2}$ Non-rhoticity took root in North America soon after it did in Britain, but it only spread to the Northeast and parts of the South. The rhotic pronunciation became the prestigious supraregional model after WWII, and non-rhoticity became sharply recessive (Labov et al. 2006: 47-48).
} 
Graph 4 presents the results regarding Question 4 from our questionnaire, which dealt with rhoticity in the speech of our experimental participants.

It should be noted at this point that participants who answered 'no' could be either fully non-rhotic (which is appropriate for SBS), or semi-rhotic, which is inappropriate for both SBS and GA. In other words, students who combine features of SBS and GA, and speak a hybrid of sorts also belong to the 'no' group in the graph below.

As seen in Graph 4, around 50\% of the participants are fully rhotic, whereas the other half displays at least some degree of non-rhoticity. Looking at the two subgroups individually we can see that $68 \%$ of students who prefer GA are fully rhotic, meaning that as many as $32 \%$ introduce the non-GA feature of non-rhoticity at least some of the time; on the other hand, almost all students who prefer SBS use non-rhoticity, but the way our question was formulated precludes us from knowing whether they are consistently non-rhotic, or, as we suspect, only partially non-rhotic. The SBS group seems more consistent when it comes to retaining the phonetic habits of native speakers of the British pronunciation model.

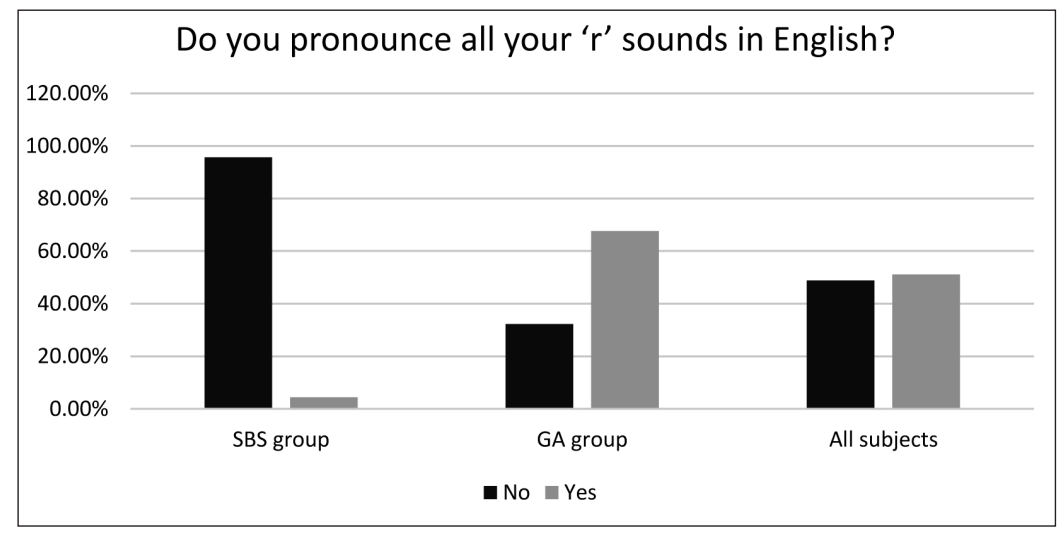

Graph 4. Rhoticity results

\subsection{T-voicing}

T-voicing or T-tapping refers to the realisation of / $t /$ as a voiced sound, typically an alveolar tap $[\mathrm{r}]$. This is a feature of North American varieties of English, GA included, where it is categorically present in the appropriate phonetic environment (it is found in syllable-final prevocalic environments, word-internally as well as across word boundaries; the preceding segment must be a sonorant, while the following segment must not be a consonant other than syllabic /1/) (Wells 1982: 248). 
Traditionally absent from SBS, this feature, however, is "increasingly reported for a minority of [SBS] speakers" (Cruttenden 2014: 178). Nonetheless, thus far it seems to have been confined to function words and a small number of very frequent non-function words, especially across word boundaries (for more details see Hannisdal 2006, Badia Barrera 2015 and Bjelaković 2018). Our participants were familiarized with T-voicing as part of their English Language 1 (Phonetics) undergraduate course and were advised to associate it only with GA. Therefore, this feature was considered to be one of the main distinguishing features between SBS and GA. Our classroom experience shows that our experimental participants readily recognise and use T-voicing in their speech, unlike T-glottaling which is mainly associated with SBS and is harder to articulate for Serbian EFL learners.

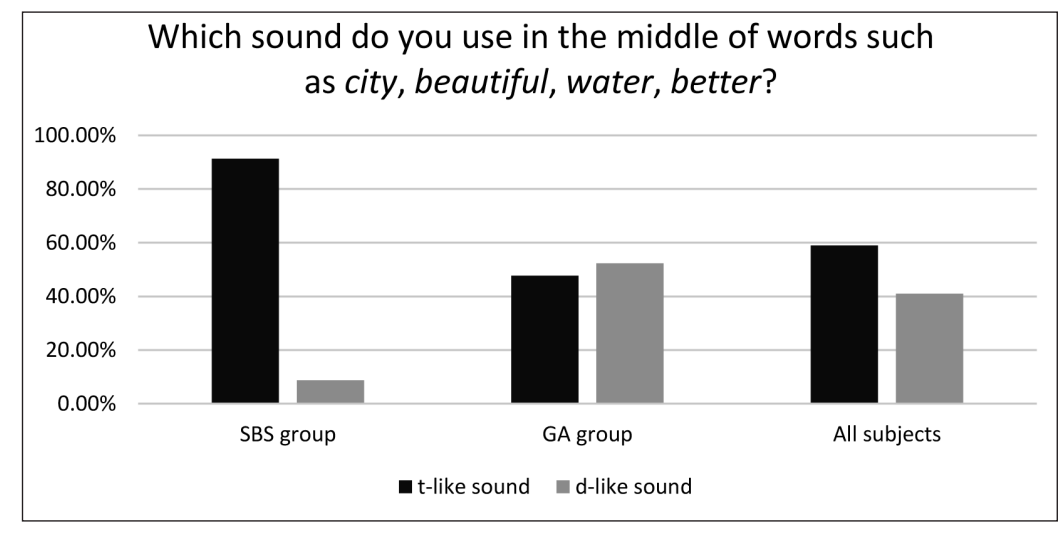

Graph 5. T-voicing results

Many instances of T-tapping in GA occur when a /t/ is flanked by any two vowels, the second of which is unstressed (Čubrović 2018: 41). This particular phonetic environment was tested in our questionnaire. As seen in Graph 5, only $10 \%$ of the SBS group report T-voicing, while the GA group is much more ambivalent: only $52.5 \%$ report using it. In other words, nearly one half of participants in the GA group report an absence of the feature appropriate for GA. Taken together, less than half (41\%) of all our participants report using T-tapping in the specified words, in which it is found word-medially in an intervocalic position.

\subsection{The Lot vowel}

A well-known difference between SBS and GA has to do with the quality of the vowel in the Lот lexical set. SBS has a short, rounded vowel, currently approaching [o] in quality (Cruttenden 2014: 126). On the other hand, GA has a longer, unrounded, 
open vowel of the [a:] type, which makes this set merged with the PALM set for most speakers of North American English (i.e. bother rhymes with father) (Wells 1982: 122; 245-246; Labov et al. 2006: 12-13).

Our questionnaire contains two questions (no. 6 and no. 9) that examine the use of the LOT vowel in our participants' speech. The results are given according to the group (SBS or GA), and then cumulatively for both groups together. In Question 6, our participants were requested to describe their vowel (o-like or a-like) in simple, high frequency words: God,job and shot. As can be seen in Graph 6, our participants were largely aware of the appropriate vowel for their chosen variety. The SBS group overwhelmingly opted for an 'o-like' sound, whereas almost 70\% of the GA group opted for an 'a-like' sound in frequent LOT words. Since the GA group was larger, the total percentage of participants preferring [a:] in this lexical set was slightly over 50\%. The fact that the GA group was larger may have skewed the cumulative results (All subjects in the graph).

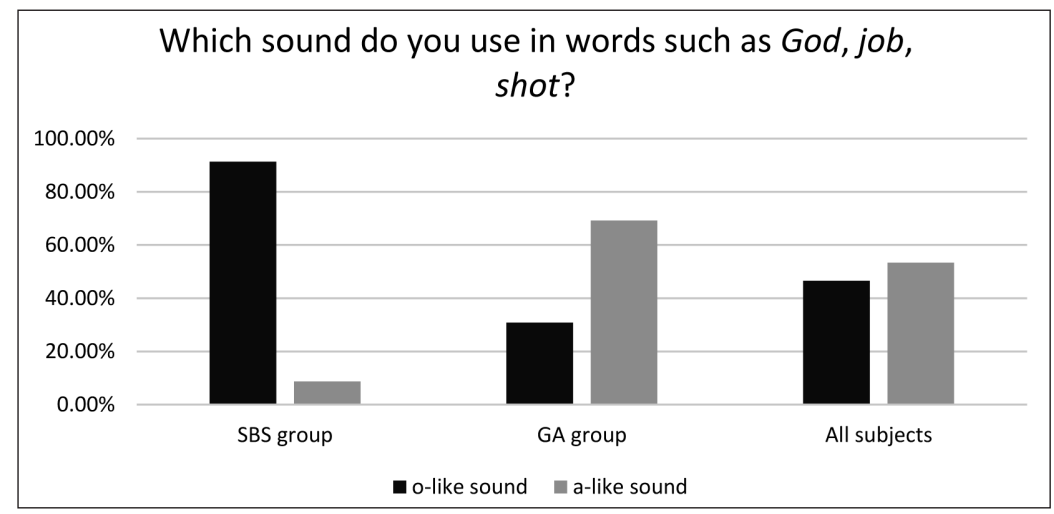

Graph 6. LOT vowel results in frequent LOT words

Another question that explores the use of the LOT vowel in our participant group deals with the vocalic realization of the vowel in the first syllable of the English word following. This word was added to the questionnaire in a separate question based on our classroom experience. Namely, more often than not, English Deparment freshmen have difficulty deciding how to pronounce this word. Moreover, they are unaware of its different phonetic realizations across the dialects of English. The results of this question are given in Graph 7. Percentages shown are very similar to those in Graph 6. What little difference can be detected between the two is in the direction we expected, i.e. fewer GA participants use [a:] in the word following (either because they are more influenced by the spelling, or because of the explicit instruction in SBS). This also proves that our participants adhere to the phonetic features of the variety of English they tend to speak. 


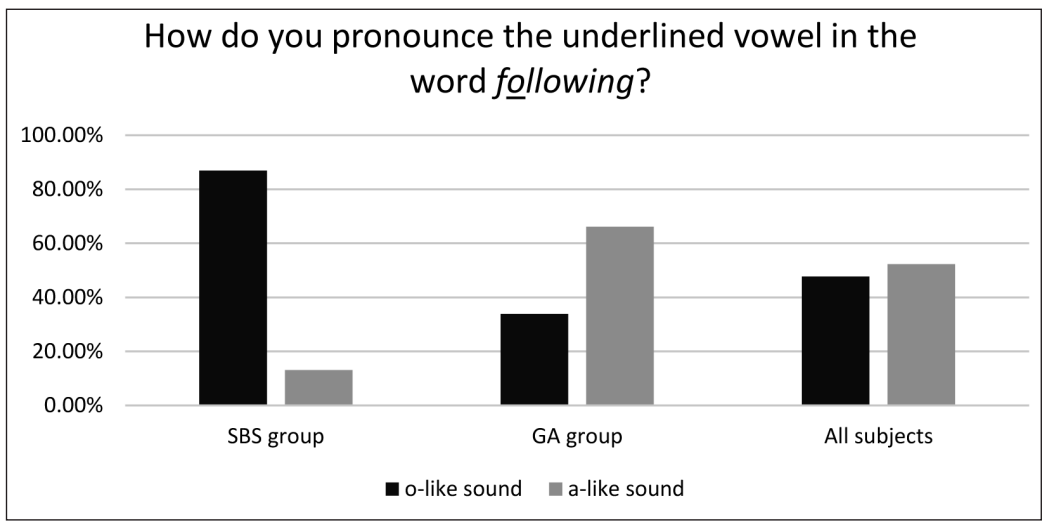

Graph 7. LOT vowel results in the word following

\subsection{The BATH vowel}

Another diagnostic feature this survey looked at was the vowel in the lexical set BATH. In this set SBS has /a:/, as in PALM ${ }^{3}$, whereas GA has /æ/ as in TRAP. The BATH vowel is also interesting on the diachronic level of analysis. It was developed through the lengthening of [a] or [æ] into [a:] due to the fricative that follows (most often /f, $\theta, \mathrm{s} /$ ) initiated at the end of the seventeenth century, e.g. staff, path, pass, ask, etc. (Cruttenden 1994: 107). Other sources of the BATH vowel include the monophthongization of the Middle English diphthong /au/ eventually to the BATH vowel in words like aunt, branch, chant, or the late Middle English loss of the velarized lateral approximant /1/ and lengthening of the vowel in half, calf (Cruttenden 1994: 107). Additionally, this lexical set comprises words that had the Middle English /a/ in front of consonant clusters like/ns/ and /nt/, e.g. dance, plant, etc.) (Lass 1999: 104, 106-107).

The results in Graph 8 indicate that all participants belonging to the SBS group use the appropriate /a:/ vowel in this lexical set, whereas only $61.5 \%$ of the GA group uses $/ \mathfrak{m} /$, the vowel appropriate for their chosen variety. In other words, more than a third of GA participants use the SBS feature in the words in question. As before, one potential reason for this could be the explicit instruction they had been exposed to. Taken together, and marked as 'All subjects' in Graph 8, slightly over half of our participants, $54.5 \%$, use the SBS /a:/like sound in this lexical set.

\footnotetext{
${ }^{3}$ However, as Wells points out, certain words "although involving an identical phonological environment, retained the short vowel" and so we have /æ/ in 'gas', 'lass', 'morass,' 'amass', 'mass' (in physics), 'crass', 'bass' etc. (Wells 1982: 232).
} 


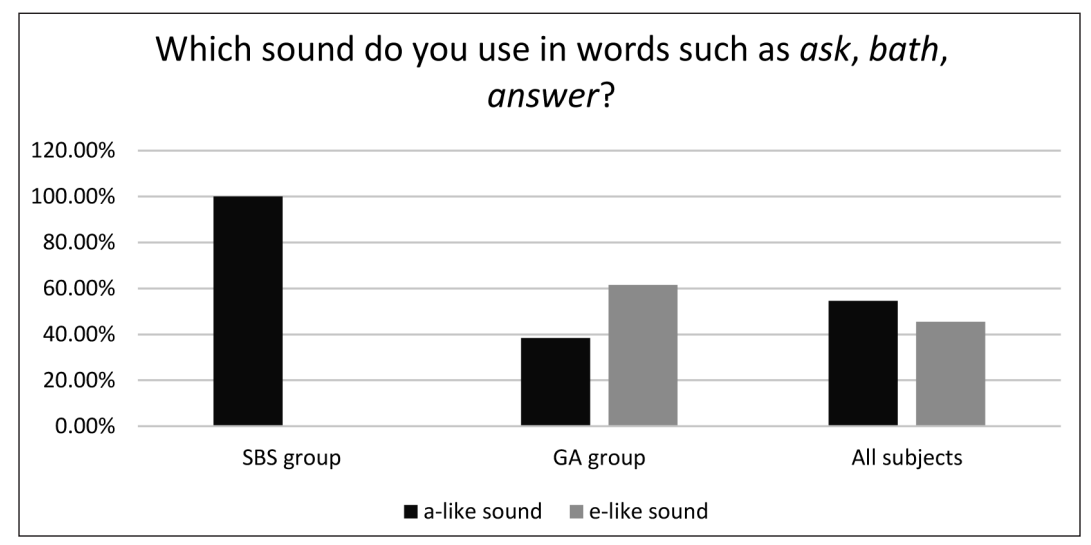

Graph 8. BATH vowel results

\subsection{The low back merger}

The low back merger, or the cot-caught merger, refers to the phonemic merger of the vowels in lexical sets LOT and тноUGHт, making pairs like cot/caught, bot/bought, hock/hawk, collar/caller, Don/Dawn, knotty/naughty, etc. homophonous. In addition to being a traditional feature of Scottish and Northern Irish varieties of English (Wells 1982: 399-402, 443), this is a feature of certain varieties of North American English; not only that, but it seems to be spreading to many other varieties thereof (Labov, Ash and Boberg 2006: 58-65). This feature is wholly absent from SBS (in which these vowels differ both in length and quality), but can be considered to be an optional feature of GA. Its optionality and instability in GA will be elaborated further here. Sociophonetic research shows that the low back merger is used in more than half of the geographic territory of North America (Labov, Ash and Boberg 2006: 60). Extensive surveys of American English dialects show that there is strong evidence to prove that:

this merger is now complete in northern New England, the West and Canada, as well as in parts of the Midland and South, [...]. It is in progress in the remaining parts of the Midland and South - more advanced in some communities and social groups than in others - and may even be making inroads among younger, upwardly mobile speakers in the areas that have historically resisted it, as the pronunciation features that prevented it in the past become socially stigmatized. (Boberg 2015: 233)

Due to the strong association of the low back merger with GA, we decided to test our experimental participants in order to find out what their attitude is towards 
this ongoing vowel process. Participants were offered two pairs of words in two separate questions (no. 7 and no. 8). The word pairs investigated were bot/bought and collar/caller; participants were expected to have a clear preference, i.e. report both pairs as having the same sound (participants with the merger), or both pairs differing (participants who keep the vowel contrast). However, the results (Graph 9) indicate that for around $20 \%$ of each group one of the word pairs sounds the same, while the other word pair sounds different (i.e. $20 \%$ of our participants said bot and bought sound the same while collar and caller sound different for them, or vice versa). Overall, the results suggest that both groups treat the low back merger similarly, with $69 \%$ and $61.5 \%$, respectively, saying these vowels were different for them. This means that, surprisingly, as many as $31 \%$ of the SBS group gave an inappropriate answer (reporting one $(22 \%)$ or both pairs $(9 \%)$ as merged), considering this feature is completely absent from SBS. For the GA group, this figure was 37.5\%. These results may suggest that, regardless of which variety they prefer speaking, our participants are on the whole somewhat insecure about this phonemic opposition, possibly due to their exposure to those subvarieties of GA that exhibit the merger.

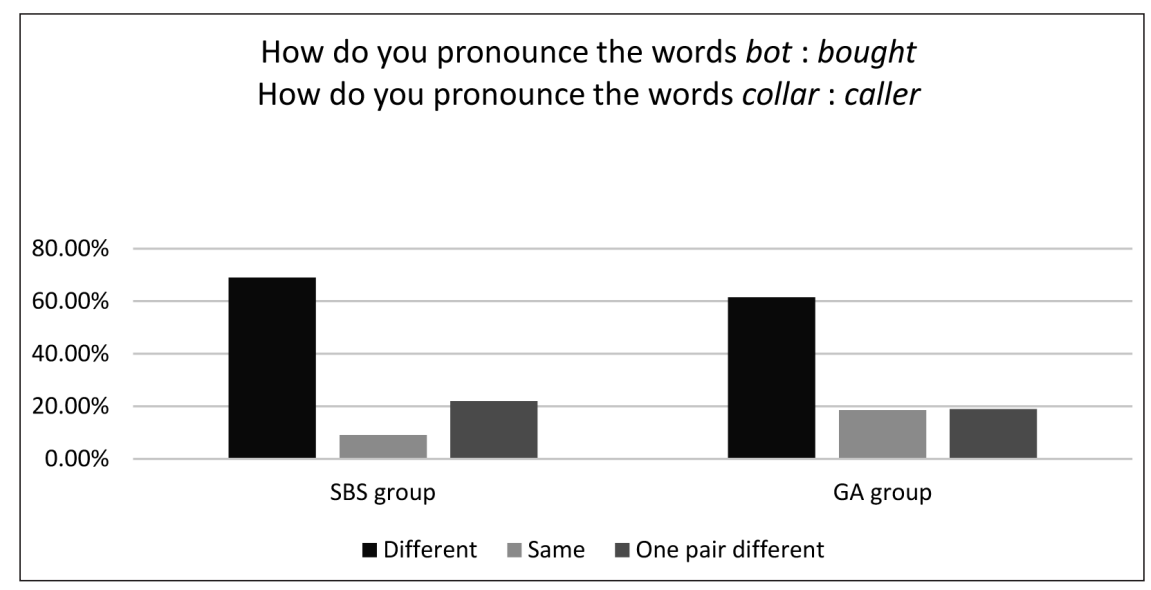

Graph 9. The low-back merger results

\section{Conclusion}

Our results show that GA is now the preferred model, at least when it comes to production (three quarters of our respondents say they prefer using it). This is undoubtedly, at least in part, due to the fact that our respondents are overwhelmingly (more than $90 \%$ of them) exposed to GA more than to SBS. When it comes to desirability, however, SBS still wins out: $66 \%$ of respondents say they prefer listening to SBS. 
It is the above-mentioned exposure to GA, coupled with our respondents' being explicitly instructed in SBS, that probably leads to mixing of the SBS and GA features we see in the results.

There is, however, a notable difference between the two groups of respondents in terms of consistency: $52 \%$ of SBS are consistent in their choice of features (i.e. they report using only SBS features), whereas as little as $20 \%$ of GA respondents consistently picked GA features. This means that some $28 \%$ of our respondents stick to their preferred pronunciation model, while the rest, over two thirds of them, use some sort of an amalgam of SBS and GA.

If we look at individual features, and take our two subgroups of respondents together ('All subjects' in the graphs above), then the following becomes apparent: $51 \%$ are fully rhotic, $41 \%$ use t-voicing, around 53\% have an [a:]-like vowel in LOT words, and $45 \%$ use /æ/ in BATH words.

\section{References}

Anastasijević, K. and A. C. Gimson (1957). Engleska fonetska čitanka: priručnik za učenje engleskih glasova, ritma i intonacije. Beograd: Nolit.

Badia Barrera, B. (2015). A Sociolinguistic Study of T-glottalling in Young RP: Accent, Class and Education. Unpublished PhD dissertation. University of Essex.

Boberg, C. (2015). North American English. In: M. Reed and J. M. Levis (eds.), The Handbook of English Pronunciation. Malden, MA: Wiley Blackwell, 284-309.

Bjelaković, A. (2018). Harry Potter and the Glottal Stop: Glottal Replacement and T-voicing in Contemporary RP. Filolog, 18, 138-153.

Čubrović, B. (2017). Low Back Merger in Native and Nonnative Speakers of American English. The Linguistics Journal, 11(1), 222-231.

Čubrović, B. (2018). Profiling English Phonetics. $4^{\text {th }}$ edition. Belgrade: Philologia.

Collins, B. and I. M. Mees (2013). Practical Phonetics and Phonology: A Resource Book for Students. $3^{\text {rd }}$ edition. London and New York: Routledge.

Cruttenden, A. (1994). Gimson's Pronunciation of English. $5^{\text {th }}$ edition. London and New York: Arnold.

Cruttenden, A. (2014). Gimson's Pronunciation of English. $8^{\text {th }}$ edition. London and New York: Routledge.

Hlebec, B. (2004). A Textbook of English Phonology. $4^{\text {th }}$ edition. Beograd: Čigoja štampa.

Jenkins, J. (2000). The Phonology of English as an International Language: New Models, New Norms, New Goals. Oxford: Oxford University Press. 
Labov, W., S. Ash and C. Boberg (2006). The Atlas of North American English. Berlin: Mouton de Gruyter.

Lass, R. (1999). Phonology and Morphology. In: R. Lass (ed.), The Cambridge History of the English Language. Vol. 3: 1476-1776, Cambridge: Cambridge University Press, 56-186.

Mihailović, Lj. (1966). The Phonemic Elements of Modern English. Beograd: Naučna knjiga.

Hannisdal, B. R. (2006). Variability and Change in Received Pronunciation. Unpublished PhD dissertation. Department of English, University of Bergen.

Vidović, V. (1967). Engleski glasovi, naglasak, ritam i intonacija. Beograd: Zavod za izdavanje udžbenika Socijalističke Federativne Republike Jugoslavije.

Wells, J. C. (1982). Accents of English. Cambridge: Cambridge University Press. 